\title{
Measuring the Impact of ISO 14001 Implementation
}

\author{
Vijay Gawaikar ${ }^{1 *}$, A. G. Bhole ${ }^{2}$, R. R. Lakhe ${ }^{3}$ \\ ${ }^{1}$ Manager, Bharat Dynamics Limited, Hyderabad, India \\ ${ }^{2}$ Former Head of Civil Engineering Department, VNIT, Nagpur, India \\ ${ }^{3}$ Director, Shreyas Quality Management System, Abhyankar Nagar, Nagpur, India
}

Received: 9 April 2017

Accepted: 23 July 2017

\begin{abstract}
This paper aims to develop a model based on ISO 14001(EMS) clauses to improve environmental performance and enhance business efficiency in Indian context. For this purpose, a questionnaire was prepared considering all the clauses to understand and arrive at better performance. Input and output variables were derived through deep study and reviewed by people involved in implementation. Based on 146 responses, the present research has resulted in a strong relationship between each clause of ISO 14001. The findings of this study confirm that input and output variables have a positive and significant relationship. The reliability and factor analysis is done by adopting SPSS software, and models are prepared for the same industries. In the present study, linear regression coefficients $\mathrm{R}=.869, .833$, and .847 , which indicates that there is strong correlation between independent and dependent variables. Multiple linear regressions were performed on five independent variables toward three dependent variables, and results for the regression models were significant, i.e., Sig. $=0.000$. The availability of resources $(0.624$ to 0.906 ) is found to be more significant for input variables among the other four variables, whereas the input variables, i.e. achievement of objective, has come out as the strongest amongst all output variables. It has been observed that Model 1 has contributed more in the present study, which proposes significant improvement after implementing the model in any sector of ISO 14001-certified industries.
\end{abstract}

Keywords: enhance, efficiency, questionnaire, clause, findings

\section{Introduction}

Rapid industrialization is the requirement of today's scenario and has resulted in various types of pollution such as air, water, noise, land, and solid waste generated through various activities of products. Most industries have been trying to cope up with the various

*e-mail: veejayshree@yahoo.com environmental aspects through various ways and means due to the existence of regulatory authorities as specified in various acts/rules.

An EMS is used to address an organization's impact on the environment. Organizations implement such systems in order to maintain compliance with environmental regulations, lower environmental costs, reduce risks, train employees, develop indicators of impact, and improve environmental performance [1]. A significant element influencing EMS improvement is the involvement of employees, without who even the 
most efficient top management is not able to realize the determined targets. Also, qualified workers' ideas are not used very often in order to improve EMS. Only stable and effectively supervised processes, as well as properly monitored significant environmental aspects, can ensure appropriate EMS improvement [2]. ISO 14001 certification/implementation has certainly proven to be an important driver for the enhancement of environmental performance [3].

Very often organizations, when taking decisions to implement an environmental management system conforming to ISO 14001, speculate about when and what benefits they can achieve. This stems from the fact that implementing and maintaining an environmental management system is an expensive process, and this management system brings positive effects in the long term [4]. An effective EMS can help a firm manage, measure, and improve the environmental aspects of its operations. EMS has the potential to lead to more efficient compliance with mandatory and voluntary environmental requirements. EMS may help companies effect a cultural change as environmental management practices are incorporated into its overall business operations [5]. Environmental performance improvements are enhanced only to the degree/extent that the system is implemented, alongside the objectives/targets and management commitment [6]. There is also a need for integrating crossfunctional activities to include environmental training of personnel. Finally, there is the need for formal procedures and the availability of these specialized procedures and information to be available to people in new product development, recycling, and pollution prevention [7].

As far as literature in this subject matter is concerned, no comprehensive review directly related to the identification of benefits arising from implementing an environmental management system according to ISO 14001 standard has been compiled. Knowledge about the benefits arising from environmental management system implementation is based on the review of literature, ISO 14000 series requirements, and surveys conducted among a group of experts in the field of environmental management [8]. In sum, while many governments promote voluntary approaches to improve the environment beyond that which is required by law, there is still much to learn about this non-regulatory approach [9]. The usefulness of EMS as a tool to manage environmental issues in companies is a question of interest to many different parties. One of the most interested groups conceivably is the companies themselves, who invest a large amount of resources into the implementation and operation of EMS. As a natural follow-up they seek to find out not only their own performance in connection to increased environmental work, but also the general value of the standardized EMS as recognized on the relevant markets [10].

It can be verified that ISO 140001 certification contributes to improving environmental management in companies. That system complies with environmental legislation and requires a commitment of the certified company to a continuous search for improvement in environmental actions [11]. Effective EMS can help facilities identify and correct regulatory problems before they become violations [12]. There has been significant awareness of global environmental problems, in particular relating to global warming, ozone depletion, biodiversity, pollution, and population growth. With this increasing awareness comes the realization that the potential impacts of proposed development activities need to be assessed and understood so that appropriate management and control strategies can be adopted [13].

In principle the implementation of EMS has a potential benefit to implement pollution prevention practices and to improve overall environmental performance and wise use of scarce resources through the implementation of ISO 14001 standards. But it is usually a big challenge for accredited industries to maintain the expected standard at all times due to lack of commitment [14]. The main aim of the procedure was to identify desirable features of the system contributing to the enterprises' better performance. The features of ISO 14001, essential for better performance, were attributed to the following stages of the environmental management system: commitment of all the workers, establishing procedures for achieving objectives and targets, establishing procedures for limiting impurities, conducting periodic internal audits, evaluating environmental performance, management reviews, and minimizing the negative influence on the environment [15].

The aim of our research is to develop a model for managing the environment through ISO 14001 (EMS) clauses, from which quantifiable indication of overall environmental performance for an organization may be established. This research establishes a methodology for the derivation of a well-defined system that provides a numeric variable, by using numerical values that have been obtained from a set of linguistic values evaluated against independent variables.

Earlier organizations were commonly classified simply according to size and the barriers they experience while implementing an ISO 14001 (EMS). This system of classification is not sufficient for understanding the multifaceted environments within which modern organizations operate. Earlier studies on Environmental management system implementation have not addressed the vital issues of the relationship between various clauses of ISO 14001 for improving organizational environmental performance along with development of an approximate generalized field data-based model. We also have observed that mostly research considered only on a manufacturing sector at a time and with very few attributes have been considered and responses collected.

In this research study, the core attributes of all the clauses of ISO 14001 have been considered and responses collected from certified industries to measure the impacts of EMS implementation on improving environmental performance. In the present research study, the models have been developed to enhance environmental performance of the ISO 14001 certified organization through SPSS. 


\section{Material and Methods}

The focus of our study was to measure the impacts of ISO 14001-certified units. This study is based on data collection from 146 respondents that was collected using a questionnaire. The questionnaire was first validated through engineers and managers. Senior managers were chosen as key informants because they are likely to be knowledgeable about the difficulties in implementing an environmental management system in organizations. We chose senior managers who were engaged in implementation issues of ISO certifications. The validity of the developed questionnaire was confirmed by a number of experts [16].

The author has covered various types of ISO 14001 industries such as power, steel, refractory, automobiles, petrochemicals, treatment plants, etc., and questionnaires were sent for collecting the response from them. The content of each variable was well represented by the measurement items employed for this particular study.

In this particular study, the majority of the respondents are found to be male from different sectors of ISO 14001-certified organizations. The average age of the respondents is 35 years and most of them have been working with their respective organizations for 20 years, and the age of the industry ranges from 10 to 20 years. Most of them have more than 20 years of experience in their respective areas. They have undergone training related to ISO 14001 - particularly on EMS awareness, waste management, legal, and other requirements, and clean technologies. ISO 14001-certified industries are located in industrially developed regions and respondents' industries have a turnover of up to 500 crore rupees.

The following sample size has been considered for perfect study and for measuring the impacts:

- For pilot study: 25

- For main study: 150 (actual data was received from 146 respondents)

As for variables and measurement, this study was carried out using a structured questionnaire survey (76 input variables) and the selection of measurement items was based on an exhaustive review of literature with detailed evaluations by the authors. Dependent variable performance was measured through 12 variables based on each clause of ISO 14001. All responses were measured using a five-point Likert-type scale with scale ranging from "strongly disagree" (1) to "strongly agree" (5). As for data analysis, statistical software analysis package SPSS version 20 was used for all major statistical analyses. Data was collected using pre-designed and structured questionnaires.

\section{Results and Discussion}

\section{Response Rate}

The characteristics of the ISO 14001 industry were based on organizational profiles: nature of the establishment, type, age, experience, trainings attended, location, and annual sales. Most of the surveyed industries were from India's Maharashtra State.

A total of 150 questionnaires were mailed to the respondents from almost 20 different ISO 14001-certified industries. With a close follow-up by telephone call, email, and personal interaction with the respondent, 146 completed questionnaires were received. The response rates through email, internet, and personal interaction were $10.27 \%, 6.16 \%$, and $83.57 \%$, respectively. In addition, a close follow-up and frequent visits to various ISO 14001 organizations also helped improve the response rate. The response rate is also considered to be good when compared to similar studies from previous research work. A majority (76.3\%) of the respondents reported that the most important benefit of implementing EMS ISO14001 is improved corporate image $($ mean $=4.35)$ with a low standard deviation of 0.556 , indicating a general consensus among the respondents [17].

Prior to administering the questionnaire, field workers had established whether these businesses had indeed implemented any green business practices. Only 298 questionnaires were returned, giving an effective response rate of $93.13 \%$ [18]. For instance, Tan (2005) conducted a study on ISO 14001 firms in Malaysia, which give a $47.4 \%$ response rate. On the other hand, Samat et al. (2006) conducted their study among service organizations in the northern region of Malaysia and also achieved a response rate of $57.71 \%$ which is significantly higher than the standard $20 \%$ acceptable mail survey response rate [19].

\section{Factor Analysis}

Cronbach's Alpha is 0.971, which means values are very much reliable and contribute more for the present research work. An overall mean score of 3.95 was recorded, indicating that employees viewed EMS adoption as a long-term affair and there must be a will to continually improve it. Cronbach's alpha for this scale is 0.87 , signifying reliability in this scale [20]. Schuessler (1971) stated that a scale is considered reliable if it has an alpha value greater than 0.60. Hair et al. (1998) added that reliability estimates between 0.60 and 0.70 represent the lower limit of acceptability in quantitative research studies. KMO measure of sampling adequacy for the items was 0.770 . Thus, the sample size of 76 is adequate and satisfactory, which means the study has a strong and required interrelationship. The KMO measure of sampling adequacy for the items was 0.869 (that is, >0.7), indicating sufficient inter-correlations of Bartlett's Test of Sphericity, which was found to be significant $($ Chi-square $=1263.085, \mathrm{p}<0.005)[21]$.

The questionnaire was pretested prior to the main survey using a sample of 10 ISO managers to determine its internal consistency, which was then analyzed by means of Cronbach's Alpha. The study adopted a cut-off of 0.7 for the Alpha score. The overall Alpha Coefficient 
obtained from the analysis of the pretest data exceeded the cutoff of 0.7 , indicating that the internal consistency of the questionnaire was strong [22].

Final Cronbach's alpha ranges from 0.7922 to 0.9498 , which means that the items/variables of all the performance measures are highly reliable [23]. This indicates that the sub-criteria have common factors. A KMO value more than 0.5 is recommended as optimal. Final Cronbach's alpha value and range of correlation coefficients is calculated using reliability analysis. Bartlett's test of sphericity should be significant $(p<0.05)$ in the factor analysis to be considered appropriate [24].

Bartlett's test is another indication of the strength of the relationship among variables. This tests the null hypothesis, i.e., correlation matrix is an identity matrix. An identity matrix is a matrix in which all of the diagonal elements are one and all off-diagonal elements are close to 0 , which is meant to reject this null hypothesis. In the present study, Bartlett's Test of Sphericity is significant (0.000). That is, significance is less than 0.05 , i.e., the significance level is small enough to reject the null hypothesis. This means that the correlation matrix is not an identity matrix.

The next item from the output is communalities that show how much of the variance (i.e., the communality value, which should be more than 0.5 to be considered for further analysis, or else these variables are to be removed from further steps factor analysis) in the variables has been accounted for by the extracted factors. For instance, more than $90 \%$ of the variance in "input variables" is accounted for.

Factor analysis with varimax rotation was carried out for the independent variables. Basically, the factor analysis with varimax rotation condensed the independent variables by almost $50 \%$. These statistical analyses confirm that the measurement scales have measured the same constructs and met the acceptable standards based on the guidelines defined by Hair et al. (2006). As for the correlation coefficients, between the independent and dependent they were less than 0.90 , indicating that the data has no serious collinearity problem [25].

Eigenvalues have been divided into three subsections, i.e., initial eigenvalues, extracted sums of squared loadings, and rotation sums of squared loadings. For analysis and interpretation purpose, we are only concerned with rotation sums of squared loadings. Here, one should note that the first factor accounts for $35 \%$ of the variance. Cumulative percentages are almost the same after component No. 38.

Results from factor analysis indicated that three significant factors with eigenvalues greater than one contributed $36.104 \%$ from the total of 20 components of the independent variables. The rotated factor matrix validated the underlying dimensions of environmental attitudes (independent variables) into three major dimensions. The three significant factors were named environmental protection (five items), government's role (three items), and personal norm (two items) [21]. In the present study the $1^{\text {st }}, 2^{\text {nd }}, 3^{\text {rd }}, 4^{\text {th }}, 5^{\text {th }}, 6^{\text {th }}, 7^{\text {th }}$ to $9^{\text {th }}, 10^{\text {th }}$ to

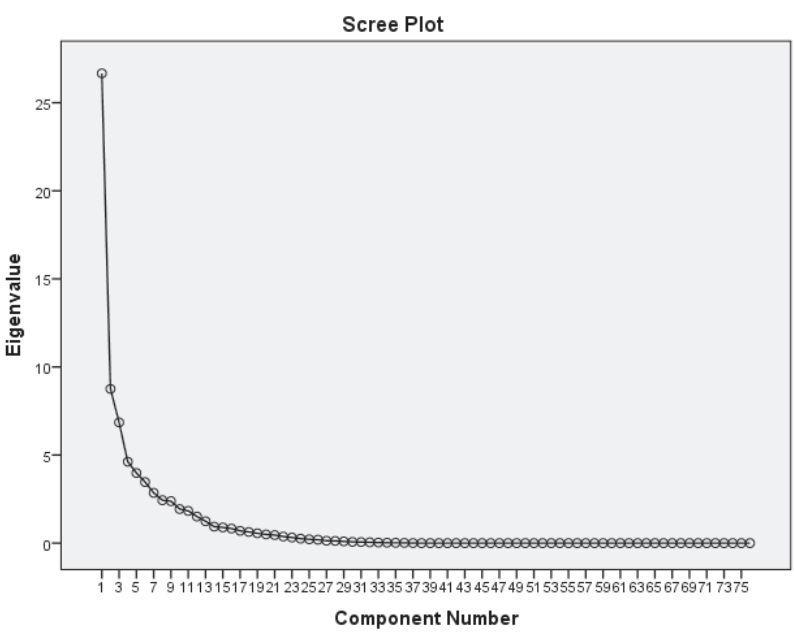

Fig. 1. Scree plot for input variables.

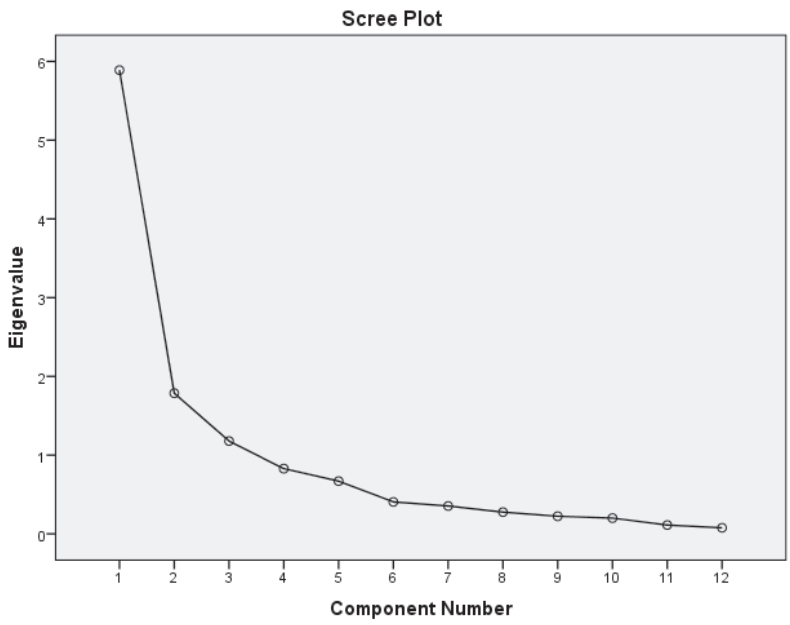

Fig. 2. Scree plot for output variables.

$11^{\text {th }}$, and $12^{\text {th }}$ to $13^{\text {th }}$ factors contributed $35 \%, 12 \%, 9 \%$, $6 \%, 5 \%, 5 \%, 3.7$ to $3.1 \%, 2.5$ to $2.4 \%$, and 1.9 to $1.6 \%$ of total variances, respectively. All the remaining factors are observed to be insignificant.

In the final part (labeled rotation sums of squared loadings), the eigenvalues of the factors after rotation arrived. Rotation has the effect of optimizing the factor structure and one consequence for these data is that the relative importance of 13 factors is equalized. Before rotation, factor one accounted for considerably more variance than the remaining $12(35.086 \%$ compared to $11.520,9.013,6.080,5.239,4.562,3.753,3.205,3.135$, $2.548,2.405,1.987$, and 1.636. However, after extraction it accounts for only $16.416 \%$ of variance (compared to $11.414,9.792,8.158,6.936,6.788,6.390,5.244,4.690$, $4.474,3.678,3.442$, and 2.747 , respectively).

The components were extracted in SPSS using principal component analysis with varimax rotation. Initially, factors with an eigenvalue greater than one were extracted and the scree plot along with the unrotated factor solution was analyzed. Those factors with a significant slope above the bend in the scree plot were extracted. 
Table 1. Independent (input) variables extracted by factor analysis.

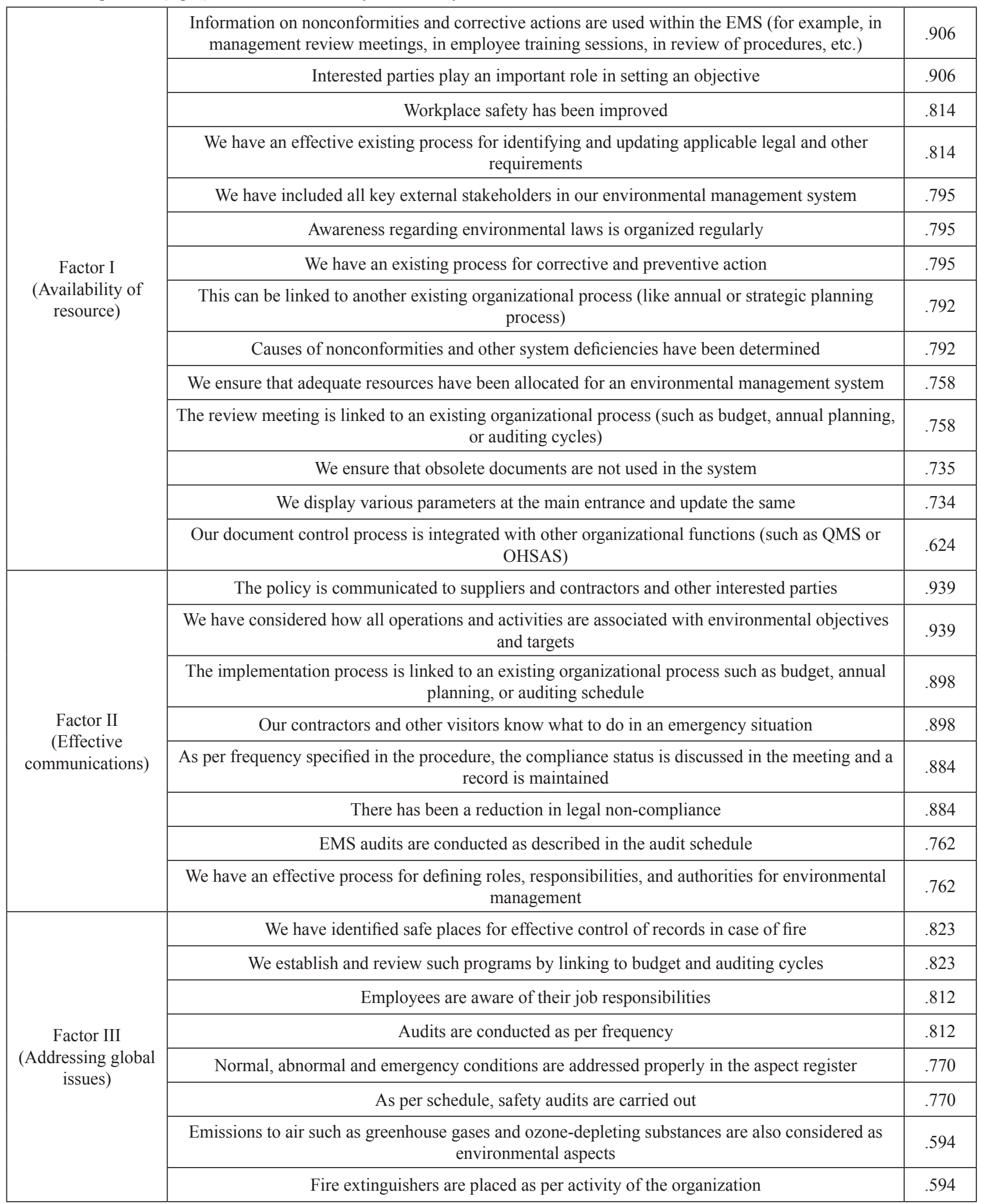


Table 1. Continued.

\begin{tabular}{|c|c|c|}
\hline \multirow{8}{*}{$\begin{array}{c}\text { Factor IV } \\
\text { (Effective process } \\
\text { of implementation) }\end{array}$} & We have considered how all operations and activities are associated with legal requirements & .845 \\
\hline & $\begin{array}{l}\text { The policy reflects the three key commitments (to compliance, prevention of pollution, and } \\
\text { continual improvement) }\end{array}$ & .845 \\
\hline & The above process can be improved further by involving outside parties & .837 \\
\hline & We have trained personnel for their roles and responsibilities during emergencies & .837 \\
\hline & Our existing process of identifying aspects is effective & .613 \\
\hline & We have reviewed our operations and activities for potential emergency situations & .613 \\
\hline & We ensure effective correspondence in case of changes in legal and other requirements & .531 \\
\hline & Compliance or legal requirements is discussed in the management review meeting & .531 \\
\hline \multirow{7}{*}{$\begin{array}{c}\text { Factor V } \\
\text { (Following } \\
\text { documented } \\
\text { procedure) }\end{array}$} & We conduct review as per frequency & .825 \\
\hline & We prepare a training calendar on the basis of requirements of employees & .825 \\
\hline & Social requirements are considered as an objective in our organization & .730 \\
\hline & $\begin{array}{c}\text { Operations and activities associated with significant environmental aspects, legal requirements, and } \\
\text { environmental objectives are identified }\end{array}$ & .730 \\
\hline & $\begin{array}{l}\text { We have identified operations an activities associated with significant environmental aspects, legal } \\
\text { requirements, and environmental objectives }\end{array}$ & .691 \\
\hline & $\begin{array}{c}\text { Our documentation is integrated with other organizational documentation (such as human resource } \\
\text { plans or quality procedures) }\end{array}$ & .449 \\
\hline & We have identified safe places for effective control of documents in case of fire & .439 \\
\hline
\end{tabular}

The scree plot graphs the eigenvalue against the factor number. From the five factors on (input variables) and three factors on (output variables), we can observe that the line is almost flat, meaning that each successive factor is accounting for smaller and smaller amounts of the total variance. It has been noted that the scree plot flattens out after the fifth and third components in input and output variables, respectively, as given in figures. Note that the scree plot and the eigenvalues support the conclusion that these 13 variables can be reduced to five components in input variables. Scree plots are shown for input variables in Fig. 1 and output variables in Fig. 2. From the curves, the number of factors appears to be 5 and 3 in input and output variables, respectively.

The outcome of component matrix shows the loadings (extracted values of each item under three variables) of the 76 variables on the five factors extracted. The higher the absolute value of the loading, the more the factor contributes to the variable (We have extracted five variables wherein the 76 items are divided into five

Table 2. Dependent (output) variables extracted by factor analysis.

\begin{tabular}{|c|c|c|}
\hline \multirow{5}{*}{$\begin{array}{c}\text { Factor I } \\
\text { (Management of } \\
\text { waste) }\end{array}$} & Effective storage, retrieval, identification, protection, retention, and disposal of record system & .815 \\
\hline & Identification and prevention of all type of pollution & .795 \\
\hline & Corrective and preventive actions are initiated to mitigate their impacts on time & .750 \\
\hline & Effective waste management & .693 \\
\hline & Relevant versions of applicable documents are available at points of use & .635 \\
\hline \multirow{4}{*}{$\begin{array}{l}\text { Factor II } \\
\text { (Better } \\
\text { compliance) }\end{array}$} & $\begin{array}{l}\text { Operations and activities are identified as associated with significant environmental aspects, legal } \\
\text { requirements, and environmental objectives }\end{array}$ & .886 \\
\hline & The organization is competent on the basis of appropriate education, training, or experience & .724 \\
\hline & Better employee efficiency & .652 \\
\hline & Compliance of legal and other requirements & .616 \\
\hline \multirow{3}{*}{$\begin{array}{c}\text { Factor III } \\
\text { (Achievement of } \\
\text { objectives) }\end{array}$} & Objectives and targets are achieved by the plant & .881 \\
\hline & $\begin{array}{l}\text { Internal communication has become effective among the various levels and functions of the } \\
\text { organization regarding environmental management }\end{array}$ & .835 \\
\hline & Improved control of documents & .477 \\
\hline
\end{tabular}


Table 3. ANOVA ${ }^{\mathrm{a}}$

\begin{tabular}{|c|c|c|c|c|c|c|}
\hline \multicolumn{2}{|c|}{ Model } & Sum of Squares & df & Mean Square & F & Sig. \\
\hline \multirow{3}{*}{1} & Regression & 49.646 & 5 & 9.929 & 42.447 & $.000^{\mathrm{b}}$ \\
\cline { 2 - 7 } & Residual & 16.140 & 69 & .234 & & \\
\cline { 2 - 7 } & Total & 65.787 & 74 & & & \\
\hline
\end{tabular}

a. Dependent Variable: Output-1

b. Predictors: (Constant), Input Factor-5, Input Factor -3, Input Factor -1, Input Factor -4, Input Factor -2

Table 4. Coefficients.

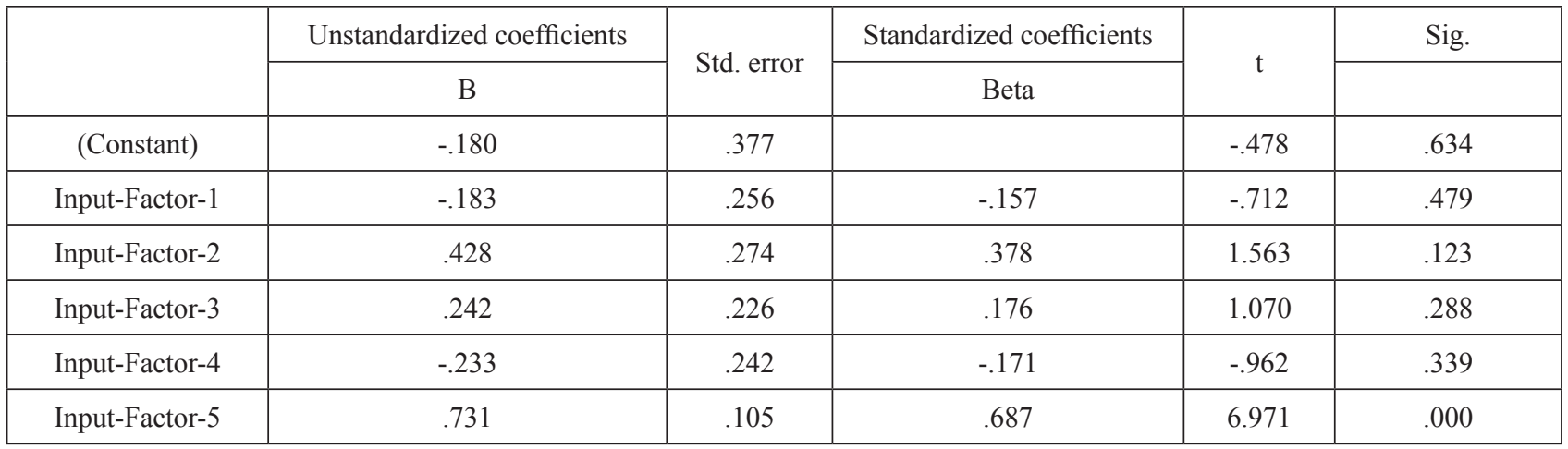

variables according to most important items with similar responses to components 1-13). Afterward, the rotated component matrix was performed. The idea of rotation is to reduce the number factors on which the variables under investigation have high loadings.

We observed in the present study that availability of resources and effective communication and effective implementation processes are falling under most important input variables. The availability of resources ( 0.624 to 0.906$)$ is found to be more significant input variables amongst other four variables. Mostly, input and output variables range from 0.7 to 0.8 and 0.6 to 0.7 , respectively. On the other hand, better compliance and achievement of objectives are found to be more significant and factor loading is observed as 0.616 to 0.886 and 0.477 to 0.835 , respectively, whereas the input variables (i.e., achievement of objectives) has come out as the strongest variable among all output variables as given below in Tables 1 and 2 .

The following attributes have been observed (having highest loading) as strongest and significant in the present study, which needs special attention for implementing and bringing further improvement in the system, which are given and discussed as:

- The policy is communicated to the supplier and contractors and other interested parties (0.939).

- An organization has considered all operations and activities are associated with environmental objectives and targets (0.939).

- Information on nonconformities and corrective actions are used within the EMS (0.906).

- The interested parties play an important role in setting an objective (0.906).
It is essential to communicate the environmental policy wherein interested parties can play a big role in developing and managing the system as per the standard. Interested parties can contribute more if they are involved in the implementation process. Objectives and targets are the backbone of the system. Hence, all relevant operations and activities are required to be considered for setting an objective at various levels of functions. Corrective actions are required to be taken whenever system demands through internal or external audits or amendment of the system. The other attributes are also observed and equally important for developing and managing the system as given in Tables 1 and 2 .

\section{Regression Analysis and Models}

Multiple regression was performed to assess the multiple correlation coefficients $(\mathrm{R})$ between a dependent variable and the eight summated scales. $\mathrm{R}$ was found to be $0.690\left(R^{2}=0.476 ; F=3.942 ; p<0.001\right)$. This result indicated that the eight scales have a high degree of criterion-related validity when taken together [26]. A new model was estimated and the assumptions underlying the regression model were tested again. The adjusted $\mathrm{R}^{2}$ of 0.900 is acceptable for this type of analysis and the model is statistically significant ( $p$ value $=0.025$ ) [27] Multiple linear regressions were performed on the five independent variables toward three dependent variables. The overall result for the regression model was significant (significance $=0.000$ ). The result of this regression is shown in Table 3 and 4.

Model summary is useful in multiple regressions and remaining part of the study. In the present study, 
$\mathrm{R}$ and $\mathrm{R}$ square value have been determined. $\mathrm{R}$ value represents simple correlation and 1.00 indicates a high degree of correlation. $\mathrm{R}$ square indicates how much of the total variation in the dependent variable can be explained by independent variables. In this case $100 \%$ can be explained, which is high [28]. The final model provides estimates of the regression parameters to test the hypothesis concerning different motivational and control variables. The $\mathrm{R}^{2}$ value of the final regression model is 0.37 and $R^{2}$ adj value is 0.32 . The predicted $R^{2}$ pre value for the final model is 0.26 . The $F$ ratio value of 8.16 of the final model demonstrates that the model is significant at $1 \%$ level of significance [29]. In the present study, the model summary includes multiple correlation coefficient $\mathrm{R}$ and its square (i.e. $\mathrm{R}^{2}$ ), and also the adjusted version of this coefficient as summary measures of the model fit. As can be seen the linear regression coefficient $\mathrm{R}=.869, .833$, and .847 , which indicates that there is strong correlation between dependent and independent variables (a figure closer to 1.000 means a strong correlation). In terms of variability, the value amount of $\mathrm{R}^{2}=.755$ or $76 \%, .694$ or $69 \%$, and .717 or $71 \%$, which explains the variability within the population (this means that $76 \%, 69 \%$, and $71 \%$ of the population in the sample agree on the correlation between the given variables).

Qualitative analysis showed that there is a positive correlation between environmental awareness of entrepreneurs/managers and environmental policy and generally with environmental practices (significant at $\mathrm{p}<0.05 ; \mathrm{r}: 0.6)$. There is some differentiation in correlation depending on what kind of practices they are. Environmental awareness is positively correlated with the implementation of environmental systems practices ISO 14001, EMAS (at $\mathrm{p}<0.05 ; \mathrm{r}-0.56$ ). Environmental awareness and the protection of natural resources practices are also positively correlated (significant at $\mathrm{p}<0.05$; $\mathrm{r}: 0.33$ ), but unfortunately there is no effect of environmental awareness for support of ecological organizations [30].

Setting the confidence interval at $99 \%$, the results of ANOVA test (Table 3) provide an F-test value for the null hypothesis. However, based on the analysis we can reject the null hypothesis where $\mathrm{F}=42.447$ of model 1 and $\mathrm{p}=0.001 \quad(\mathrm{P}<0.01)$, wherein confidence interval is by default set at $99 \%$.

We look into two values: $F$ and the Sig. A high F value means that there is more chance of the null hypothesis being rejected and the alternate being accepted. Here it is 42.447 of model 1 , which means that the values are pretty high. On the other hand, the significance tells us the confidence level of accepting the alternate hypothesis. A significance value of $0.004<0.005$ indicates that the correlation is statistically significant [31]. Here the Sig is 0.000 for all models, which means the alternate hypothesis is accepted. It is understood that both the F value and the Sig. value that the two variables are indeed different from each other and that they affect outputs 1 , 2 , and 3 in a different manner. Table 4 tells us about the structure of the model. The analysis of the same is:
Input factors 1 and 4 have a negative relationship with output factor 1 , and input factors 2,3 , and 5 have a positive relationship with output factor 1 of model 1 .

The values of $R^{2}$ were more than 0.9930 for 24 provinces of Iran. The radiation-based methods estimated the reference evapotranspiration near the Caspian Sea better than the other regions. The most precise methods were the Berengena-Gavilan, modified Priestley-Taylor, and Priestley-Taylor methods for the provinces ES (central Iran), GI and GO (northern Iran), and the StephensStewart method for IL (western Iran). Finally, a list of the best performances of each method is presented to use other regions and next research steps according to the values of mean, maximum, and minimum temperature, relative humidity, solar radiation, elevation, sunshine, and wind speed. The best weather conditions to use radiation-based equations are 23.6-24.6 $\mathrm{MJ} \mathrm{m}^{-2}$ day $^{-1}$, 12$20^{\circ} \mathrm{C}, 18-24^{\circ} \mathrm{C}, 5-13^{\circ} \mathrm{C}$, and $<180$ hour month ${ }^{-1}$ for solar radiation, mean, maximum, and minimum temperature, and sunshine, respectively [32]. In our current research, models 1,2 , and 3, and the relational variables (include control variables) cumulatively have contributed .755 per cent (.76x100), .694 per cent $(.694 \times 100)$, and .717 per cent (.717x100) of the variance, respectively. This percentage of the variance can be explained by the predictor variables. The results showed that ISO 14001 EMS implementation $(ß=-.157, p<.01),(\beta=-.125, p<.01)$, and $(\beta=-.180, p<.01)$ were found to be significant. According to the present study, models such as management of waste (Model 1), better compliance (Model 2), and achievement of objective (Model 3) have been developed. Management of waste and achievement of objective are observed to be more significant and have contributed more compared to the remaining one, i.e., better compliance. This means that special care needs to be taken for managing various types of waste such as hazardous and non-hazardous waste. Smart objectives must be achieved at the required timeframe, which may appropriately benefit the system. The author has studied and discussed all the models:

- Management of Waste $=-0.180+(-0.183 \times$ InputFactor- 1$)+(0.428 \times$ Input-Factor- 2$)+(0.242 \times$ InputFactor-3) $+(-0.233 \times$ Input-Factor- 4$)+(0.731 x$ InputFactor-5).

- Better Compliance $=-0.192+(-0.157 \times$ Input-Factor-1 $)$ $+(0.508 \times$ Input-Factor-2) + (-0.130 x Input-Factor-3)

$+(0.189 \times$ Input-Factor-4) $+(0.627 \times$ Input-Factor-5)

- Achievement of Objective $=0-879+(-0.157 \times$ InputFactor-1 $)+(0.193 x$ Input-Factor- $)+(-0.009 x$ InputFactor-3) $+(0.370 \mathrm{x}$ Input-Factor- 4$)+(0.417 \mathrm{x}$ InputFactor-5).

\section{Conclusions}

This study empirically investigated the relationships between the 76 input variables on 12 dependent variables. The following conclusions and recommendations can be put forth based on the analysis of variance between these variables. 
The above findings are distinctively important as it is solely based on various clauses of ISO 14001 in Indian context, which are different from previous studies that focus mainly on other environment sectors in developed countries. The sample size of 76 is found to be adequate and satisfactory, which means the study has gotten strong and required interrelationships.

From the study, the number of factors arrived are 5 and 3 as input and output variables, respectively, which are also demonstrating intact relationships among various variables and measurement of ISO 14001 impacts is influenced by input and output variables, namely availability of resources, effective communications, addressing global issues, effective process of implementation, following documented procedure, managing waste, better compliance, and achieving objectives.

The ISO 14001 clauses such as (i) objective, targets and programmes, (ii) resources, role, responsibility and authority, and (iii) internal audits are the most important variables that influenced the study. We have observed through the present study that the availability of resources is found to be more significant with input variables among the other four variables. Whereas the input variables (i.e., achievement of objectives) has come out as the strongest variable among all output variables. In our entire study, the significance is less than 0.05 , i.e., the significance level is small enough to reject the null hypothesis. This means that the correlation matrix is not an identity matrix.

More importantly, the outcome of the study is limited to input and output factors covering all required attributes from each clause. The author has tried to cover all the clauses and prepared attributes address the clauses that are very lengthy. The analysis obtained above is very helpful for getting required and expected results through the model questionnaire, which is the outcome of the input and output variables.

The study will definitely encourage the implementation of the model questionnaire for achieving further improvement in ISO 14001 (EMS). The derived model in this study provides further improvement in existing environment performance of ISO 14001-certified organizations. The derived model can be used in any manufacturing sector as well as service sectors.

It was observed that some of the respondents are not fully aware of the ISO 14001 clauses in certified industries. Due to this, the development of the model will not be perfect for achieving better performance through the derived model. The sample taken - which covers only a few companies and not all the varieties of ISO 14001 certified industries - means that the resulting model questionnaire may not be up to the mark to have expected improvement in the system.

Some of the respondents have expressed difficulties because of the time-consuming process on the lengthy questionnaire, which needs to be properly studied for being made shorter for obtaining perfect and timely responses. It is also understood that coordination between the top management, environmental representatives, or core teams and the other staff is essential for maintaining the environmental management system.

Furthermore, the present study and research is based on ISO 14001:2004 (EMS), which is valid up to September 2018. This study can be performed for the ISO 14001:2015 standard for getting the model to the next improvement level in the system.

In India, the implementation could be improved further, especially in the service and manufacturing sectors with a large sample size of 300 or more with more response from the various organizations. We also recommend extending the research to other industries such as educational institutions, hotels, or more polluted industries in India.

Further research needs:

- Involvement of more people in the system is required because all the employees were not able answer the questions prepared based on the clauses.

- All the ISO 14001-certified industries should conduct quiz tests in a year (perhaps on World Environment Day) to improve participation and knowledge in the system.

- Involvement of top management and providing required resources for giving a boost to the system and employees.

- Models can be derived in three sectors, i.e., small, medium, and large, and then improvements can be compared and judged based on responses through the questionnaire.

\section{Acknowledgements}

I am very thankful to my family members and $\mathrm{Ph} . \mathrm{D}$. guides for extending cooperation for my research works. I extend my gratitude to Shri Ramdeobaba College of Engineering and Management, Nagpur, India for guiding me in this regard. I also want to forward may sincere acknowledgements to the ISO 14001-certified industries for submitting their value-add responses based on the input and output variables and model questionnaire. I would also like to give special thanks to the management of Maharashtra Power Sector, India as most of the responses were collected from them and devoted their precious time for my research work.

\section{References}

1. LUCIA BEDNÁROVÁ, NATÁlIA JERGOVÁ, Benefits from Environmental Management System Implementation, Óbuda University e-Bulletin 5 (1), 2015.

2. ALINA MATUSZAK-FLEJSZMAN, Factors for Improving Environmental Management Systems in Polish Companies According to ISO 14001, Polish J. of Environ. Stud. 20 (3), 709, 2011.

3. BERNARD FEI-BAFFOE, GODSGOOD K. BOTWEKOOMSON, ISAAC FIMPONG MENSA-BONSU, ERIC APPIAH AGYAPONG Impact of ISO 14001 Environmental Management System on Key Environmental Performance 
Indicators of Selected Gold Mining Companies in Ghana, Journal of Waste Management, Volume 2013, 2013.

4. MATUSZAK-FLEJSZMAN Benefits of Environmental Management System in Polish Companies Compliant with ISO 14001, Polish J. of Environ. Stud. 18 (3), 411, 2009.

5. ROBERT P., SROUFE STEVEN A., MELNYK, GYULA VASTAG Environmental Management Systems as a Source of Competitive Advantage, Department of Marketing and Supply Chain Management Michigan State University, 1998.

6. MORROW D., RONDINELLI D. Adopting corporate environmental management systems: Motivations and results of ISO 14001 and EMAS certification, European Management Journal, 20 (2), 159, 2002.

7. SROUFE R., Effects of environmental management systems on environmental management practices and operations, Production and Operations Management, 12, 416, 2003.

8. NEHA BINDAL, DWIVEDI A.K. Performance Evaluation Using Environmental Management System In Pharmaceutical Industry, Journal Of Industrial Pollution Control, 2012.

9. TOSHI H. ARIMURA, NICOLE DARNALL, RAMA GANGULI, HAJIME KATAYAMA, The Effect of ISO 14001 on Environmental Performance: Resolving Equivocal Findings, Journal of Environmental Management, 2015.

10. NAWROCKA D., PARKER T., Finding the connection: environmental management systems and environmental performance, Journal of Cleaner Production 17, 601, 2009.

11. FERNANDO MAGNANI CERVELINI, MARIA TEREZA SARAIVA SOUZA A contribution of the Cleaner Production Program to the ISO 14001 Management System: a case study in the metal-mechanic sector, Journal of Operations and Supply Chain Management 2 (1), 61, International Conference of the Production and Operations Management Society, 2009.

12. MATTHEW POTOSKI, ASEEM PRAKASH, Green Clubs and Voluntary Governance: ISO 14001 and Firms' Regulatory Compliance, American Journal of Political Science, 49 (2), 235, 2005.

13. MEENA CHAVAN, An appraisal of environment management systems: A competitive advantage for small businesses, Management of Environmental Quality: An International Journal, 16, 444, 2005.

14. ALEBEL ABEBE, Does ISO 14001 accreditation reduces environmental impact of industries: A case study in Addis Ababa, Ethiopia, Open Journal of Water Pollution and Treatment 1 (1), 2014.

15. FURA BARBARA, Improving ISO 14001 Environmental Management Systems, Polish Journal of Environmental Studies, 22 (6), 1711, 11p., 2013.

16. ALI MOROVATI-SHARIFABADI, ALIREZA NASER SADRABADI, MAHSA NAMAKSHENAS-JAHROMI, Evaluation of the Effective Factors on Organizational Success in Implementation of Environmental Management System (EMS), International Journal of Economy, Management and Social Sciences, 3 (12), 816, 2014.

17. HASLINDA ABDULLAH, CHAN CHIN FUONG The Implementation of ISO 14001 Environmental Management System in Manufacturing Firms in Malaysia, Asian Social Science, 6 (3), 2010.

18. SMITH E.E., PERKS S. A perceptual study of the impact of green practice implementation on the business, functions Southern African Business Review, 14, 2010.
19. GOH YEN NEE, NABSIAH ABDUL WAHID The Effect of ISO 14001 Environmental Management System Implementation on SMEs Performance: An Empirical Study in Malaysia, Journal of Sustainable Development, 2010.

20. LOW H.H., TAN O.K., CHOI S.L., RABEATUL HUSNA A.R. The Adoption of Environmental Management System in Malaysia's Manufacturing Organizations, Journal of Economics, Business and Management, 3 (1), 2015.

21. TAN BOOI CHEN, LAU TECK CHAI, Attitude towards the Environment and Green Products: Consumers' Perspective, Management Science and Engineering. 4, 27, 2010.

22. ELIZABETH WAGITHI WAMAI \& JAMES M.KILIKA, ISO 14001 Environmental Management Systems Certification, Firm Characteristics and Performance of Certified Firms in Nairobi County, Kenya, Journal of Management and Strategy 7 (4), 2016. LAU TECK-CHAI AND CHOE KUM-LUNG Consumers' Acceptance of Unethical Consumption Activities: Implications for the Youth Market, International journal of marketing studies, 1 (2), 2009.

23. DIGALWAR, SANGWAN Development and validation of performance measures for world class manufacturing practices in India, Journal of advance manufacturing systems, 2007.

24. SAMADHAN P. DESHMUKH Development and Validation of Performance Measures for Green Supplier Selection in Indian Industries, International Journal of Modern Engineering Research, 3, 1617, 2013.

25. HAIR J., BLACK B., BABIN B., ANDERSON R., TATHAM R. Multivariate Data Analysis (6 ${ }^{\text {th }}$ edition). Upper Saddle River, NJ: Prentice-Hall, 2006.

26. ERIC S.W. CHAN, SIMON C.K. WONG, Motivations for ISO 14001 in the hotel industry, Tourism Management; 481, 2006.

27. IENCIU IONEL-ALIN, Analyze of Environmental Disclosure Within European Union Countries, Journal of Knowledge Management, Economics and Information Technology, 2012.

28. VAISHALI MADAN, SHUBHANGI BORKAR Qualitative Agriculture Product Analysis Based SPSS Software \& Management using Cloud Computing, International Journal of Innovative Science, Engineering \& Technology, 2, 11, 2015.

29. NEELAM SINGH, SURESH JAIN, PRATEEK SHARMA, Motivations for implementing environmental management practices in Indian industries, Ecological Economics 109, $1,2015$.

30. OKSANA SEROKA-STOLKA Proactive Environmental Management and Practices in Small and Medium Enterprises (SMES) - A Resourced-Based Perspective, http://www.infoma.fri.uniza.sk/archive/mse/v2n2/079-082. pdf accessed online Feb 2017.

31. OSUGA VINCENT, ET AL., Reuse, Remanufacturing and Environmental Performance: Analysis of Timber Processing Firms in Nakuru County, Science Innovation, 32, 2015.

32. MOHAMMAD VALIPOUR Study of different climatic conditions to assess the role of solar radiation in reference crop evapotranspiration equations, Archives of Agronomy and Soil Science, 61 (5), 2015. 